\title{
Alternating Hemiplegia of Childhood: A Series of Genetically Confirmed Four Cases from Southern India with Review of Published Literature
}

\author{
Naveen Kumar Bhardwaj ${ }^{10}$ Vykuntaraju K. Gowda ${ }^{1} \quad$ Ashwin Vivek Sardesai ${ }^{1}$ \\ ${ }^{1}$ Department of Pediatric Neurology, Indira Gandhi Institute of Child \\ Health, Bengaluru, Karnataka, India \\ Address for correspondence Vykuntaraju K. Gowda, DM, Department of \\ Pediatric Neurology, Indira Gandhi Institute of Child Health, \\ Bengaluru 560029, Karnataka, India (e-mail: drknvraju08@gmail.com). \\ J Pediatr Genet 2021;10:111-115.
}

\begin{abstract}
Keywords

- alternating hemiplegia of childhood

- plegic attacks

- ATP1A3 gene

Alternating hemiplegia of childhood (AHC) is a rare autosomal dominant neurodevelopmental disorder with mutation on ATP1A3 gene. Delay in diagnosis and inappropriate diagnosis are common. In this article, we described four genetically confirmed AHC patients to provide an improved understanding of the disorder. First symptom in two patients was seizures and in other two patients was abnormal eye deviation. All had onset of plegic attacks within the first 18 months of their life. Tone abnormalities and movement disorders were present in all patients. Electroencephalogram was abnormal in two patients and all had normal magnetic resonance imaging of the brain. Response to treatment of plegic attacks was poor and also epilepsy was drug resistant. All cases had significant development delay and disability as of last follow-up. Although there is no effective treatment so far, early diagnosis is required to avoid unnecessary treatment.
\end{abstract}

\section{Introduction}

Alternating hemiplegia of childhood (AHC) is a rare autosomal dominant genetic disorder with incidence of $1: 1,000,000$ births. $^{1}$ It is characterized by transient episodes of hemiplegia/hemiparesis, quadriparesis, movement disorders, seizures, and autonomic dysfunction in isolation or in combination lasting for minutes to days. ${ }^{2-4}$ Developmental delay is seen in most of the patients and seizures are present in $50 \%$ of the patients. ${ }^{2,5,6}$ It was first described in 1971 and the diagnostic criteria for this clinical syndrome were laid down in 1993, referred to as Aicardi criteria. ${ }^{2}$ In $75 \%$ of the cases, mutations are found in the ATP1A3 gene. There is a great variability in presentation of this syndrome and is often misdiagnosed as cerebral palsy or seizure disorder. ${ }^{7}$ There are few isolated case reports from India on AHC. ${ }^{8,9}$ Here, we described clinical features, follow-up, and response to treatment of four genetically confirmed AHC patients along with a short review of literature to give better insight into this disorder.

received

May 8, 2020

accepted

June 19, 2020

published online

August 13, 2020

\section{Materials and Methods}

A retrospective chart review of children who were diagnosed with AHC on outpatient or inpatient basis in a tertiary-care pediatric hospital in South India was conducted. Retrieval of data was done from electronic medical record of the hospital, and also, patients were contacted telephonically in absence of recent follow-up visit. Patients who were suspected of having AHC clinically and confirmed by genetic studies were included in the study. Targeted next-generation sequencing was done in all cases and confirmed by Sanger sequencing. Sorting Intolerant From Tolerant and Polyphen-2 were used for in silico prediction of pathogenicity of missense mutations. Details such as sociodemographic data, clinical features, findings of neurological, electroencephalogram (EEG) and imaging studies, treatment received, and outcome were collected on a pro forma and results were analyzed. Seizures were diagnosed and defined by treating pediatric neurologist on the basis of semiology of the ictal event and epilepsy response was

(c) 2020. Thieme. All rights reserved. Georg Thieme Verlag KG, Rüdigerstraße 14,

DOI https://doi.org/ 10.1055/s-0040-1714702. 70469 Stuttgart, Germany 
categorized into drug resistant, epilepsy resolved, seizure free, or undetermined response according to the International League Against Epilepsy criteria. ${ }^{10,11}$ Ethical clearance was obtained from the institutional ethics committee of Indira Gandhi Institute of Child Health, Bangalore. Parental consent was obtained for all the four patients retrospectively, including for submission of the video of one child.

\section{Results}

Four children including three girls diagnosed with AHC were included in the study (-Table 1). All had onset of plegic attacks before 18 months of age (range: 2-15 months) and most of these episodes were lasting for 1 to 3 days. Fever was reported as provoking factor in case 3. Typical attacks usually began during awake state, with or without deviation of eyes, sweating (case 2), and posturing of body in cases 1,3 , and 4 , followed by weakness of one side or all four limbs. Eye deviation was mostly upward, but deviation to side and sometimes staring episodes were also noticed by family members. The weakness following the episode was reported variable from attack to attack. Patients used to remain conscious during typical attack and there was no increase in feeding difficulty from baseline because of these episodes. - Video 1 shows typical attack in case 1. Residual weakness on left side was seen in case 1 at the time of first evaluation. In cases 1 and 4, seizures would mostly occur as isolated events and different from the typical plegic attacks. Magnetic resonance imaging scans of the brain were done in all cases during first year of life and were normal. At first visit or during follow-up, all children were found to have some kind of movement disorders. Only case 1 has achieved independent ambulation and he is having ataxia.

\section{Video 1}

Video of alternating hemiplegia of childhood episode: In this video, there is uprolling of eyeball seen during classical episode. There is also weakness of left side of body as child is not able to move his left lower limb despite stimulus. Online content including video sequences viewable at: https://www.thieme-connect. com/products/ejournals/html/10.1055/s-00401714702.

Course of patients is described in - Fig. 1. Case 1 was seen at 5 years of age for the first time, he was having development quotient of 30 to $40 \%$, and motor impairment was more pronounced than cognitive delay. During subsequent visits, the child followed a static course. Cases 2 and 3 had quite catastrophic course during follow-up with progressive regression of motor and cognitive milestones. Case 4 is recently diagnosed and on initial presentation, there is significant delay. Case 1 had combined generalized and focal epilepsy and in case 4 , there were only right focal seizures with impaired awareness. Cases 2 and 3 were initially treated as epilepsy. Case 2 was diagnosed as drug-resistant epilepsy and had received multiple antiepileptic medications for almost 1 year till the plegic attacks appeared when she was appropriately diagnosed.

Response of plegic episodes to flunarizine or other add on drugs was poor in three of four patients based on parental questionnaire addressing decrease in frequency, severity, and duration of episodes. Case 3 had single plegic attack during last 1 year, but episodes of eye deviation were persisting. There was significant reduction in seizures frequency in case 1 from earlier one to two episodes per month to once in 5 to 6 months presently. Seizures in case 4 are still uncontrolled despite multiple medications. None of these patients has had status epilepticus.

\section{Discussion}

Children with AHC often have delay in diagnosis and possibility of misdiagnosis as there is significant variability in symptomatology and overlap of multiple symptoms. In typical cases, diagnosis of this disorder is mainly based on clinical symptoms and signs as per diagnostic criteria (- Table 2 ). ${ }^{12}$ All patients in our series were fulfilling these criteria.

Pathophysiology of AHC remains unclear, but basic science research suggests that it is a complex and multifactorial disorder. The ATP1A3 gene encodes for the $\alpha 3$ subunit of $\mathrm{Na}^{+}, \mathrm{K}^{+}$-ATPase (NKA) ion transporter, which regulates membrane excitability in neurons. Dysfunction of NKA leads to increased excitability, marked dysfunction in GABA-ergic inhibition, and altered neuronal network physiology. ${ }^{13-16}$

Clinical course of AHC has been described in three phases. Phase 1 is seen during first year of life in which there are predominant eye movement abnormalities, dystonic episodes, and some plegic attacks. Phase 2 starts after 1 year and lasts till 5 years of age. This phase manifests predominantly with increased frequency of plegic attacks, seizure episodes, and loss of developmental milestones. Phase 3 is characterized by persistent developmental delay, fixed deficits, and decreased frequency of typical attacks. ${ }^{2,7}$ Similarly, in our series, cases 2 to 4 are worsening with time as seen in phase 2 , and case 1 is having static course after 5 years of age.

In larger cohorts, abnormal eye movements are described as one of the earliest and commonest sign of AHC with frequency of 93 to $100 \%{ }^{2,4}$ In our series, cases 2 and 3 had abnormal deviation of eyes as initial presentation at 2 to 3 months of age. Various eye movements have been described in the literature such as deviation, nystagmus, jerking, unconjugated gaze, and uprolling with frequency varying from study to study. ${ }^{3,7}$ Provoking factors for typical plegic attacks include excitement, fatigue, hot weather, and fever in $75 \%$ patients. ${ }^{7}$ In our series, only case 3 had fever as provoking factor for episodes. All patients in our series had recurrent attacks of hemiparesis with shift of side and quadriparesis attacks lasting up to 72 hours, while different cohorts describe longer episodes lasting for up to 2 to 3 weeks. ${ }^{3,4}$

Most of the published series describe near normal to severe motor and cognitive delay in AHC depending on 
Table 1 Characteristics of patients with alternating hemiplegia of childhood

\begin{tabular}{|c|c|c|c|c|}
\hline Characteristics & Case 1 & Case 2 & Case 3 & Case 4 \\
\hline Age at first symptoms onset & $6 \mathrm{mo}$ & $3 \mathrm{mo}$ & $2 \mathrm{mo}$ & Day 9 of life \\
\hline Age at first evaluation & $5 y$ & $11 \mathrm{mo}$ & $2 \mathrm{mo}$ & $1.2 \mathrm{y}$ \\
\hline Present age & $9 y$ & 3 y 4 mo & $5 y$ & $1.5 \mathrm{y}$ \\
\hline Sex & Male & Female & Female & Female \\
\hline $\begin{array}{l}\text { Family history: } \\
\text { consanguinity/similar history }\end{array}$ & No & No & No & No \\
\hline Migraine in family & No & Yes (mother) & No & No \\
\hline Initial presenting symptom & $\begin{array}{l}\text { Generalized seizures, focal } \\
\text { seizures right side with } \\
\text { impaired consciousness }\end{array}$ & Eye deviation & Eye deviation & $\begin{array}{l}\text { Neonatal right clonic } \\
\text { seizures }\end{array}$ \\
\hline Type of attacks & $\begin{array}{l}\text { Left hemiplegic, sometimes } \\
\text { double hemiplegic, upward } \\
\text { gaze }\end{array}$ & $\begin{array}{l}\text { Eye deviation, dystonia, } \\
\text { hemiplegic left > right }\end{array}$ & $\begin{array}{l}\text { Eye deviation, hemiplegic } \\
\text { on either side }\end{array}$ & $\begin{array}{l}\text { Hemiplegic on either side, } \\
\text { double hemiplegic }\end{array}$ \\
\hline $\begin{array}{l}\text { Onset of hemiplegic, } \\
\text { double hemiplegic attacks }\end{array}$ & $8 \mathrm{mo}$ & $15 \mathrm{mo}$ & $2-3 \mathrm{mo}$ & $8 \mathrm{mo}$ \\
\hline Frequency of attacks/mo & $2-3$ & $3-4$ & $1-2$ & $1-3$ \\
\hline Length of attack & $1-2 d$ & $<24 \mathrm{~h}$ & $1-2 d$ & $2-3 d$ \\
\hline Seizures & Present & Not present & Not present & Present \\
\hline Autonomic disturbances & None & Sweating & None & None \\
\hline Provoking factors & None & None & Fever & None \\
\hline Relieving factors & Sleep & Sleep & Sleep & Sleep \\
\hline \multicolumn{5}{|l|}{ Examination (present) } \\
\hline Head circumference & Normal & Microcephaly & Normal & Normal \\
\hline Tone & Increased & Increased & Decreased & Decreased \\
\hline Reflexes & Brisk & Brisk & Brisk & Brisk \\
\hline Residual hemiparesis & Left sided & No & No & No \\
\hline Orofacial Dyskinesia & Yes & Yes & Yes & No \\
\hline Dystonia & Present & Absent & Present & Present \\
\hline Choreoathetosis & Present & Absent & Absent & Absent \\
\hline Ataxia & Present & Absent & - & - \\
\hline Ambulation & Present & Present with support & Not present & Not present \\
\hline $\begin{array}{l}\text { Motor function as per } \\
\text { GMFCS-E and R }\end{array}$ & GMFCS-II & GMFCS-III & GMFCS-IV & GMFCS-IV \\
\hline \multicolumn{5}{|l|}{ Investigations } \\
\hline EEG & Normal & $\begin{array}{l}\text { Right temporal slowing } \\
\text { during episode of } \\
\text { weakness }\end{array}$ & Normal & Left frontal discharges \\
\hline MRI of the brain & Normal & Normal & Normal & Normal \\
\hline $\begin{array}{l}\text { Genetic analysis } \\
\text { ATP1A3 gene-exon/ } \\
\text { nucleotide change/ } \\
\text { amino acid change }\end{array}$ & $\begin{array}{l}21 / \\
\text { C. } 2878 G>G / A / \\
\text { G960R }\end{array}$ & $\begin{array}{l}17 / \\
\text { C. } 2401 \mathrm{G}>\mathrm{A} / \\
\mathrm{D} 801 \mathrm{~N}\end{array}$ & $\begin{array}{l}17 / \\
\text { C.2440G }>A / \\
D 814 N\end{array}$ & $\begin{array}{l}17 / \\
\text { C. } 2440 \mathrm{G}>\mathrm{A} / \\
\mathrm{D} 814 \mathrm{~N}\end{array}$ \\
\hline \multicolumn{5}{|l|}{ Treatment } \\
\hline $\begin{array}{l}\text { Antiseizures drugs/ } \\
\text { response to treatment }\end{array}$ & $\begin{array}{l}\text { Topiramate, valproate, } \\
\text { clobazam/drug-resistant } \\
\text { epilepsy }\end{array}$ & Initially treated as seizures & Initially treated as seizures & $\begin{array}{l}\text { Valproate, levetiracetam, } \\
\text { clobazam, carbamazepine/ } \\
\text { drug-resistant epilepsy }\end{array}$ \\
\hline $\begin{array}{l}\text { Treatment for } \mathrm{AHC} \\
\text { attacks/response to } \\
\text { treatment }\end{array}$ & $\begin{array}{l}\text { Flunarizine, aripiprazole, } \\
\text { promethazine, } \\
\text { topiramate/poor }\end{array}$ & $\begin{array}{l}\text { Flunarizine, aripiprazole, } \\
\text { promethazine, topiramate/ } \\
\text { poor }\end{array}$ & $\begin{array}{l}\text { Flunarizine, topiramate for } \\
\text { last } 1 \text { y only staring episodes, } \\
\text { no hemiplegic episode }\end{array}$ & Flunarizine/- \\
\hline
\end{tabular}

Abbreviations: AHC, alternating hemiplegia of childhood; EEG, electroencephalogram; GMFCS-E and R, gross motor function classification system, expanded and revised; MRI, magnetic resonance imaging.

genotype and paralleling with severity of other manifestations. ${ }^{3,7,17}$ Similarly, in our series, all children are having moderate to severe developmental delay and in case 1 , motor impairment was more as compared with cognitive im- pairment. Motor function of children in our series was ranging from levels II to IV as per gross motor function classification system, expanded and revised. ${ }^{18}$ Masoud et al used various scales to study motor disabilities in a 


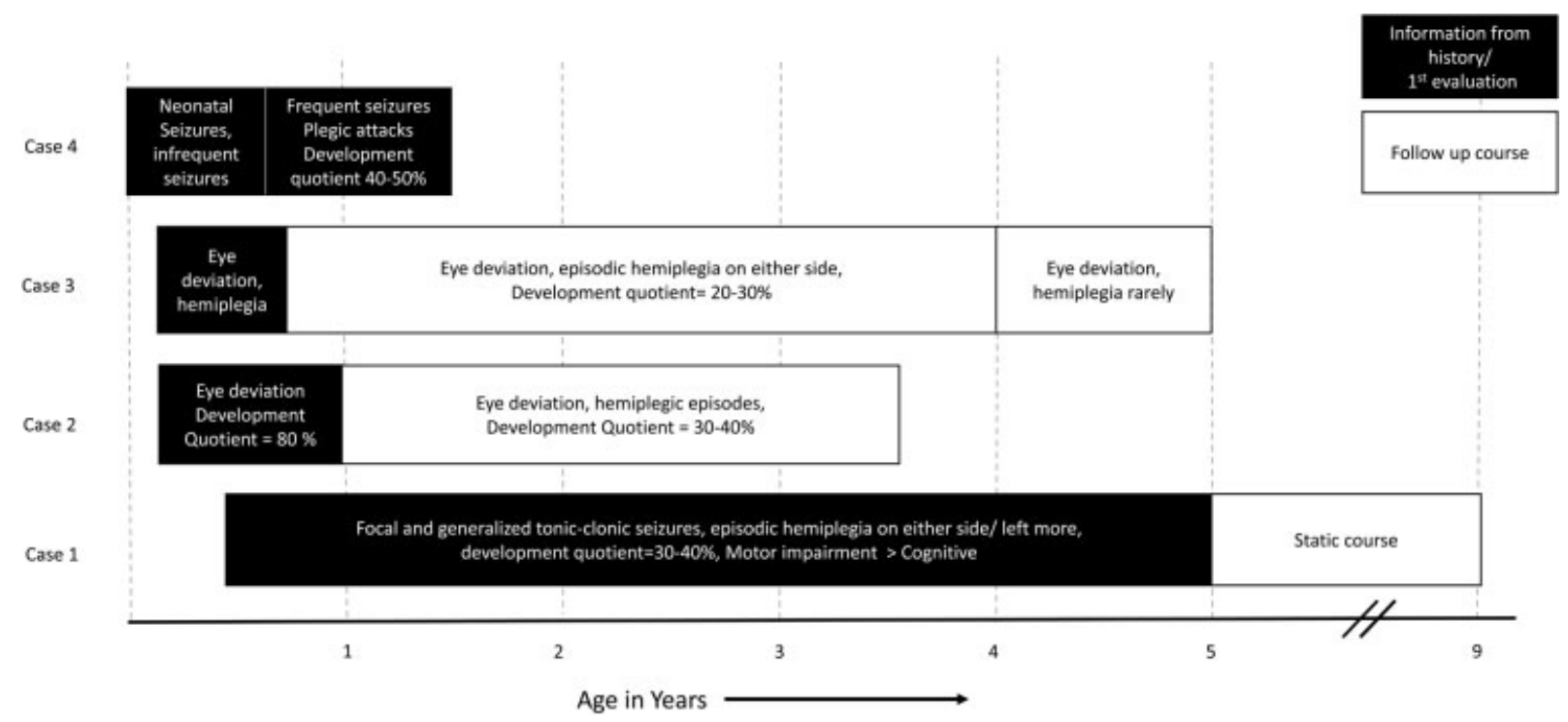

Fig. 1 Course of patients with alternating hemiplegia of childhood.

Table 2 Diagnostic criteria for classical $\mathrm{AHC}^{1}$

\begin{tabular}{|c|l|}
\hline 1 & Onset of symptoms before 18 mo of age \\
\hline 2 & $\begin{array}{l}\text { Repeated attacks of hemiplegia involving either side of } \\
\text { body }\end{array}$ \\
\hline 3 & $\begin{array}{l}\text { Other paroxysmal disturbances including tonic or dystonic } \\
\text { spells, oculomotor abnormalities, and autonomic } \\
\text { phenomena during bouts in isolation }\end{array}$ \\
\hline 4 & $\begin{array}{l}\text { Episodes of bilateral hemiplegia or quadriplegia as } \\
\text { generalization of a hemiplegic episodes or bilateral from } \\
\text { beginning }\end{array}$ \\
\hline 5 & $\begin{array}{l}\text { Immediate disappearance of symptoms upon sleeping } \\
\text { which may later resume after walking }\end{array}$ \\
\hline 6 & $\begin{array}{l}\text { Evidence of developmental delay and neurological } \\
\text { abnormalities including choreoathetosis, dystonia or ataxia }\end{array}$ \\
\hline
\end{tabular}

Abbreviation: AHC, alternating hemiplegia of childhood.

cohort of 23 AHC patients and identified oropharyngeal function as the most severely affected domain, less involvement of upper extremity functions, and no worsening of motor functions noticed with advancing age. ${ }^{19}$ It is still not clear whether motor delay is a primary feature of the syndrome, or it is secondary to other manifestations. ${ }^{3,16}$ Various neuropsychological issues, including attention deficit hyperactive disorders, defiant behavior, separation anxiety, temper tantrums, moodiness, head banging, etc., have also been described in AHC. ${ }^{6}$

Seizures in AHC are described to be focal or generalized in almost $50 \%$ of the patients. ${ }^{2}$ Two children are having seizures in our series and both of them had seizures as first presenting symptom. Likewise, Uchitel et al in a cohort of 51 patients concluded that epileptic seizures may be the first paroxysmal symptom, status epilepticus is common, and EEG may become epileptiform only on follow-up. ${ }^{5}$ In our series, case 4 had abnormal EEG on initial presentation and none had status epilepticus.
Movement disorders such as dystonia, choreoathetosis, and ataxia were present in all our patients either singly or in combination, and likewise, they are described in more than two-thirds of the patients in published literature. ${ }^{4,7}$ Differential diagnosis of AHC should include hemiplegic migraine, epilepsy, moyamoya disease, pyruvate dehydrogenase deficiency, mitochondrial disorders, neurotransmitter disorders, glucose transporter defects, and these can be ruled out with careful clinical evaluation and ancillary investigations such as appropriate metabolic tests and MRI of the brain. ${ }^{2,16} \mathrm{MRI}$ is not diagnostic of AHC and in early course of disease, it is usually normal. ${ }^{3}$ Similarly, in all our patients, MRI scans done during first year of life were normal. Nonspecific cerebral atrophy, generalized cortical atrophy, mesial temporal sclerosis, or cerebellar atrophy has been reported in a few cases of AHC. 3,20

Most common genetic mutations in ATP1A3 gene in large cohorts include D801N, E815K, and G947R. ${ }^{21}$ With addition of newer mutations, Rosewich et al introduced the notion of mutational clusters. ${ }^{22}$ Panagiotakaki et al outlined such five mutational clusters in their cohort. Phenotypic similarities have been observed within mutational clusters. ${ }^{4}$ Frequency and severity spectrum of three most common mutations in decreasing order have been graded as E815K $>$ D801N $>$ G947R in various published series. ${ }^{4,21-23}$ Two novel pathogenic missense variations in our series, D814N and G960R, belong to the same cluster as E815K and G947R, respectively. Cases 3 and 4 with $\mathrm{D} 814 \mathrm{~N}$ mutation in our series (belonging to the same most severe mutational cluster as E815K) were more severe compared with case 1 with G960R who is ambulatory, and case 2 with D801N variant had intermediate severity being able to walk with support.

Treatment strategies include treatment of acute episodes (paroxysmal epileptic or nonepileptic), preventive medication to decrease the frequency, duration, and severity of episodes along with multidisciplinary care for neuro-disabilities. Duke AHC foundation has provided detailed management guidelines for acute management. ${ }^{2,24}$ Acute management focuses on 
avoiding modifiable triggers and induction of sleep with buccal or nasal midazolam and rectal diazepam. In preventive therapy, flunarizine is most widely used agent with data available mostly from case series and few controlled trials. In different studies, it has been found effective in 50 to $80 \%$ of patients in reducing the frequency and duration of episodes by 30 to $50 \%{ }^{4,7,24}$ None of our patients responded well to treatment with flunarizine. Other agents, such as topiramate, ketogenic diet, triheptanoin, steroid, amantadine, aripiprazole, oral adenosine triphosphate, coenzyme $\mathrm{Q}$ acetazolamide, etc., have been tried with various rates of success. ${ }^{24}$ For treatment of epilepsy in AHC, there are no trials for assessing superiority of one drug over another. Topiramate is usually first preferred agent as it also improves plegic attacks. Drug-resistant epilepsy in AHC can respond to vagal nerve stimulation (VNS), ${ }^{5}$ but none of our patient received VNS.

We did this study as a retrospective analysis, so there are some limitations as data were collected through questionnaire and record review. There is potential for record bias and inaccurate reporting in such analysis, although all patients were seen by a single pediatric neurologist during the whole time. For better correlation of findings, to use objective scales for frequency of attacks, epilepsy, and treatment effects, a prospective study is indeed required.

\section{Conclusion}

Although AHC is a rare disorder, it can be diagnosed on the basis of accurate history and clinical examination. This disorder is predominantly sporadic, and till now, there is no effective treatment, but early diagnosis should be done to avoid use of unindicated and potentially harmful medications such as multiple antiepileptic drugs and to help prognostication.

\section{Authors' Contributions}

N.K.B. and A.V.S. collected data. N.K.B. prepared the initial draft of manuscript and reviewed the literature. V.K.G. conceived the study. V.K.G. and A.V.S. performed critical review of the manuscript and edited the manuscript. Final version of the manuscript was approved by all authors.

Funding

None.

Conflict of Interest

None declared.

\section{References}

1 Neville BG, Ninan M. The treatment and management of alternating hemiplegia of childhood. Dev Med Child Neurol 2007;49(10): 777-780

2 Masoud M, Prange L, Wuchich J, Hunanyan A, Mikati MA. Diagnosis and treatment of alternating hemiplegia of childhood. Curr Treat Options Neurol 2017;19(02):8

3 Sweney MT, Silver K, Gerard-Blanluet M, et al. Alternating hemiplegia of childhood: early characteristics and evolution of a neurodevelopmental syndrome. Pediatrics 2009;123(03):e534-e541
4 Panagiotakaki E, De Grandis E, Stagnaro M, et al; Italian IBAHC Consortium; French AHC Consortium; International AHC Consortium. Clinical profile of patients with ATP1A3 mutations in alternating hemiplegia of childhood-a study of 155 patients. Orphanet J Rare Dis 2015;10:123

5 Uchitel J, Helseth A, Prange L, et al. The epileptology of alternating hemiplegia of childhood. Neurology 2019;93(13):e1248-e1259

6 Jasien JM, Bonner M, D'alli R, et al. Cognitive, adaptive, and behavioral profiles and management of alternating hemiplegia of childhood. Dev Med Child Neurol 2019;61(05):547-554

7 Mikati MA, Kramer U, Zupanc ML, Shanahan RJ. Alternating hemiplegia of childhood: clinical manifestations and long-term outcome. Pediatr Neurol 2000;23(02):134-141

8 Padmanabha H, Goswami JN, Sahu JK, Swaboda KJ, Singhi P. Alternating hemiplegia of childhood with novel features. Indian J Pediatr 2017;84(06):473-474

9 Sharawat IK, Saini L. Recurrent focal seizures and transient hemiparesis: think about alternating hemiplegia of childhood. Pediatr Neurol 2018;80:97-98

10 Fisher RS, Acevedo C, Arzimanoglou A, et al. ILAE official report: a practical clinical definition of epilepsy. Epilepsia 2014;55(04): 475-482

11 Kwan P, Arzimanoglou A, Berg AT, et al. Definition of drug resistant epilepsy: consensus proposal by the ad hoc Task Force of the ILAE Commission on Therapeutic Strategies. Epilepsia 2010;51(06): 1069-1077

12 Andermann F, Aicardi J, Vigevano F, eds. Alternating Hemiplegia of Childhood. New York: Raven Press; 1995

13 Helseth AR, Hunanyan AS, Adil S, et al. Novel E815K knock-in mouse model of alternating hemiplegia of childhood. Neurobiol Dis 2018;119:100-112

14 Hunanyan AS, Helseth AR, Abdelnour E, et al. Mechanisms of increased hippocampal excitability in the $\mathrm{Mashl}^{+/-}$mouse model of $\mathrm{Na}^{+} / \mathrm{K}^{+}$-ATPase dysfunction. Epilepsia 2018;59(07):1455-1468

15 Snow JP, Westlake G, Klofas LK, et al. Neuronal modeling of alternating hemiplegia of childhood reveals transcriptional compensation and replicates a trigger-induced phenotype. Neurobiol Dis 2020;141:104881

16 Tenney JR, Schapiro MB. Child neurology: alternating hemiplegia of childhood. Neurology 2010;74(14):e57-e59

17 Pisciotta L, Gherzi M, Stagnaro M, et al; I.B.AHC Consortium. Alternating hemiplegia of childhood: pharmacological treatment of 30 Italian patients. Brain Dev 2017;39(06):521-528

18 Gross Motor Function Classification System Expanded and Revised. Robert Palisano, Peter Rosenbaum, Doreen Bartlett, Michael Livingston, CanChild Centre for Childhood Disability Research, McMaster University 2007. Available at: https://canchild.ca/system/tenon/assets/attachments/000/000/058/original/GMFCS-ER_English.pdf. Accessed June 1, 2020

19 Masoud M, Gordon K, Hall A, et al. Motor function domains in alternating hemiplegia of childhood. Dev Med Child Neurol 2017; 59(08):822-828

20 Sasaki M, Ishii A, Saito Y, Hirose S. Progressive brain atrophy in alternating hemiplegia of childhood. Mov Disord Clin Pract (Hoboken) 2017;4(03):406-411

21 Viollet L, Glusman G, Murphy KJ, et al. Correction: alternating hemiplegia of childhood: retrospective genetic study and genotype-phenotype correlations in 187 subjects from the US AHCF Registry. PLoS One 2015;10(08):e0137370

22 Rosewich H, Ohlenbusch A, Huppke P, et al. The expanding clinical and genetic spectrum of ATP1A3-related disorders. Neurology 2014;82(11):945-955

23 Capuano A, Garone G, Tiralongo G, Graziola F. Alternating hemiplegia of childhood: understanding the genotype-phenotype relationship of ATP1A3 variations. Appl Clin Genet 2020;13:71-81

24 Samanta D. Management of alternating hemiplegia of childhood: a review. Pediatr Neurol 2020;103:12-20 